\title{
ARTículo
}

\section{España Fiel: ¿La hipoteca hispana de Manuel Gómez Morín?}

\section{España Fiel: The hispanic mortgage of Manuel Gómez Morín?}

\section{Diego Martín Velázquez Caballero}

Benemérita Universidad Autónoma de Puebla golda21@hotmail.com

\section{Xóchitl Patricia Campos López}

Benemérita Universidad Autónoma de Puebla campospaty@yahoo.com

\section{RESUMEN}

El estudio analiza el tipo de hispanidad humanista que constituye el proyecto político de Manuel Gómez Morín. Ambas perspectivas, que envuelven un aroma conservador, han servido para sembrar la semilla en la tierra de diferentes autoritarismos; empero, también guardan anhelos libertarios de la gente de todos los tiempos. El humanismo de Gómez Morín es fiel al hispanismo, con todo y lo que ello implica. Para una adecuada interpretación del pensamiento político de Gómez Morín, de sus críticas a la revolución mexicana y sus propuestas de cambio para México, se hace necesario valorar el proyecto de este personaje.

Palabras Clave: Hispanidad; España; Primorriverismo; Derecha; México; Manuel Gómez Morín.

\section{ABSTRACT}

The study analyzes the type of humanistic hispanic that constitutes the political project of Manuel Gómez Morín. Both perspectives, which involve a conservative scent, have served to sow the seed in the land of different authoritarianisms; however, they also hold libertarian yearnings for the people of all times. The humanism of Gómez Morín is faithful to Hispanism, with everything and what it implies. For an adequate interpretation of Gómez Morín's political thought, his criticisms of the Mexican revolution and his proposals for change for Mexico, it is necessary to evaluate the project of this politician.

Keywords: Hispanism; Spain; Primorriverism; Right; México; Manuel Gómez Morín.

(C) Los autores. Este artículo es publicado por ISHRA, Revista del Instituto Seminario de Historia Rural Andina de la Facultad de Ciencias Sociales de la Universidad Nacional Mayor de San Marcos. Este es un artículo de acceso abierto, distribuido bajo los términos de la licencia Creative Commons Atribucion - No Comercia Compartir Igual 4.0 Internacional. (http://creativecommons.org/licenses/by-nc-sa/4.0/) que permite el uso no comercial, distribución y reproducción en cualquier medio, siempre que la obra original sea debidamente citada. 


\section{Introducción}

Desde el descubrimiento de las Indias Occidentales (América) por el Imperio español, se forjó una relación indisoluble entre ambos que ha revestido distintas tendencias sujetas a razones culturales, comerciales y de control, que van desde la dependencia, la reciprocidad en términos de igualdad, hasta el rechazo, y que se reproducen en ambas tierras fomentando la formación de grupos en torno a cada orientación, así como la confrontación entre ellos.

La hispanidad trata de evidenciar que Latinoamérica y España tienen varios elementos en común; sin embargo, para los sectores más radicales del conservadurismo, dicho elemento cultural debe transformarse en hispanismo castizo y catolicidad intransigente. Observar su influencia en México frente a otras maneras de vivir la hispanidad y la mexicanidad arrojará el déficit de la modernidad mexicana. El hispanismo castizo es empleado como una cobertura críptica donde varios personajes ocultan sus preferencias conservadoras y de derechas. Para el caso iberoamericano, particularmente para México, calificar a alguien de derecha supone un apego a valores específicos. La importancia de la hispanidad castiza en el desarrollo del pensamiento político mexicano radica en que, como elemento de cohesión de México y España, constituye una categoría de interpretación para entender las condiciones del desarrollo ideológico en la derecha. Manuel Gómez Morín, fundador del Partido Acción Nacional e intelectual representativo de esta tendencia política, constituye un referente que no puede faltar en el estudio del hispanismo católico.

Es necesario mitigar la leyenda negra de las cosas, pero, también inhibir sus narrativas blanca y rosa. Hay mucho trabajo por hacer para historiar y analizar a las derechas en la república mexicana. Como parte de este ejercicio, el Partido Acción Nacional y Manuel Gómez Morín requieren atención. Buena parte de los trabajos que abordan la fundación del PAN evaden las tendencias hispanistas e hispanófilas de algunos de sus fundadores y aceptan sólo alguna simpatía por el catolicismo social. El sentido común indica que la verdad rebasa estos puntos simples.

Cabe el debate de Soledad Loaeza (1999) con la imagen que algunos deconstruyen respecto del liberalismo gomezmoríniano. Nunca se manifestó Gómez Morín como un católico intransigente; pero nunca dejó de apoyarlos. La exposición que hace en España fiel: En cursivas. (Gómez, 1973) no sólo es la defensa de un tipo peculiar de hispanidad sino también de un criptocatolicismo. Así como Manuel Gómez Morín tiene una hipoteca religiosa, tiene también una hipoteca hispana. Aunque Gómez Morín no representa la mentalidad propia del catolicismo intransigente, como lo señala Soledad Loaeza (2009), el precio de su hipoteca religiosa fue mantener y sostener a los grupos y personajes representativos del hispanismo criollo, católico e intransigente. Hay que notar que muchos de estos grupos se infiltran y apoderan de organizaciones, instituciones, espacios y sociedades. La hipoteca católica de Gómez Morín es la norma que ha tenido que seguir México y América Latina (Barajas, 2014 y Rodríguez, 2014).

Interpretar hermenéutica e históricamente el trabajo intitulado España Fiel, permite encontrar directrices y señales de esta hispanidad castiza y católica. Este estudio inicia explorando el concepto de hispanidad para luego describir el contexto histórico en México que va de 1920 a 1940. Posteriormente se hace un señalamiento de las condiciones que acercaron a Gómez Morín con esta hipoteca hispanista y, finalmente, se hace un análisis de contenido de la obra.

\section{Suspiros de España}

El Hispanoamericanismo, en su vertiente conservadora, fue orientándose a otra tendencia: la Hispanidad, que conjuga como elementos característicos el idioma, la raza y la religión. Estos 
elementos, que dan cuenta del vínculo cultural y espiritual entre España y América Latina, serán tomados como una herramienta política durante el régimen de Miguel Primo de Rivera. En parte, para formar una comunidad cultural y espiritual entre España y sus excolonias americanas; así como para contener el auge de los nacionalismos periféricos. ${ }^{1}$

La Hispanidad es un concepto elástico, tan flexible que siempre da la imagen de desaparecer. De suyo, el concepto es neutro; empero, su condición en un conjunto de repúblicas prosaicas como las latinoamericanas impacta, la mayor parte de las veces, a los personajes que se sienten custodios de preservar la cohesión identitaria. La observación de este tipo de personajes obliga a considerar la obra de Solange Alberro (1992). El acierto que el título contiene, enuncia la experiencia multicultural del que tiene que olvidar la identidad para coexistir. Para el libanés Amin Maalouf (2012) las identidades matan, es decir, vuelven un fastidio la existencia en contextos que cada vez son más complejos y divergentes. Cuando las identidades quedan al margen, la gente se comporta en modo pacífico. La asimilación se convierte en una necesidad vital.

Alberro señala circunstancias gastronómicas, sexuales, económicas, lúdicas, culturales y de supervivencia en general, donde los españoles convivían pacíficamente con indígenas, negros, judíos y musulmanes, olvidando su condición natural, origen e identidad. Quizá por esto la convivencia, la fiesta, es importante en Latinoamérica; la pachanga nos hace transparentes. Sin embargo, allí donde la integración entre los españoles y las castas tomaba tintes cotidianos, la burocracia eclesiástica era la más incisiva en fomentar las divisiones y segregaciones, haciendo llamados al orden, la cristiandad y la hispanidad. Desde entonces se pueden encontrar los elementos del pensamiento conservador que más tarde caracterizarán a un sector de la población en Hispanoamérica. Aun cuando la autora afirma que las castas indígenas, mestizas y afroamericanas adoptaban también un comportamiento españolizante, lo cierto es que, históricamente, existe una diferencia bien marcada entre los caracteres latinoamericanos y españoles. Con todo, el texto de Solange Alberro genera un indicador de la exclusión que guarda el sentido de la hispanidad castiza y católica.

La cotidianidad hace que el español peninsular olvide su identidad en suelo americano, que se confunda con los demás; empero, las instituciones religiosas, económicas y políticas hacen que el criollo se convierta en un gachupín, es decir, que resucite ese purismo arrogante, clasista, racista y excluyente que lo empodera para imponerse frente a los demás. Aunque el texto de Alberro procura exculpar de su racismo a los españoles, finalmente, no lo consigue. Las prácticas castizas y puristas españolas siempre conciertan en exaltarse y menospreciar otros hábitos locales; pero hispánicos también. El cosmopolitismo es aún bien distante de los hispanistas; en retórica, prácticas, creencias y usos.

En el conservadurismo latinoamericano dicha hispanidad casticista subsiste de muchas formas. La perspectiva española católica se transforma en hispanofilia. Desde el momento de la emancipación latinoamericana, la dificultad de catalizar las propuestas de una modernidad liberal y republicana generó frustraciones y complejos que siempre hacían voltear hacia el pasado, al orden, las estructuras y las instituciones que, más o menos, habían generado estabilidad: la Colonia y los regímenes autoritarios conservadores. Al momento mismo de la independencia, la Madre Patria siempre se constituyó como un modelo que servía de brújula cuando la modernidad se profundiza. Los grupos conservadores, no obstante que anhelan la modernidad liberal en su sentido económico, vuelven la mirada a España como proyecto primigenio de orden que configura una civilización. Es la fuente donde abrevan quienes regresan cuando las aventuras 1 Estas ideas son recurrentes en estudiosos como Lida (2001), Pérez, R. (2001), Pérez, T. (2010) y Mateos \& Sánchez (2011).. 
modernizadoras fracasan. Empero, reconstruir dicho orden, implica enmendar la estratificación social colonial, castiza y barroca.

Es importante tomar en cuenta que el hispanismo casticista se desarrolla en México desde la época colonial. La estructura social colocó en el vértice a peninsulares y criollos; la asignación de los privilegios poco cambió. La forma en que la hispanidad se plantea, de pronto, tiene que ver con los mecanismos que los peninsulares impusieron para consolidar su hegemonía. Es necesario recordar que, posterior a la independencia, muchos grupos criollos no buscaban generar una nación sino, solamente, sustituir a los peninsulares. La idea de la Patria del Criollo (Martínez, 1998) viene a convertirse en el producto de una serie de revanchismos y venganzas. La hispanidad, así, se vuelve un pagaré que ampara una deuda infinita.

El centenario de las independencias en las repúblicas latinoamericanas fue una oportunidad para atenuar el rencor y la reserva contra España. Situación que, además, puede afirmarse, nunca ha sido absoluta. Simplemente pasa que cada quien tiene su España. No obstante, este aniversario en América Latina implicó que el Imperio Español intentara una recuperación espiritual y cultural de sus antiguas colonias (Pérez, 2005). Así, el hispanismo encontró en la cultura, el romanticismo y las críticas hacia la modernidad liberal, una forma de proyectarse y lo hizo efectivamente. El centenario de las independencias latinoamericanas coincide con la pérdida de las últimas posesiones españolas. De ahí se derivó la oportunidad para replantear un discurso imperialista, y aún hegemónico, que tomó la cultura como instrumento para una nueva evangelización española: la hispanidad. Debe señalarse que este nuevo nacionalismo español también tiene connotaciones económicas. No obstante que muchos empresarios españoles se devolvieron a España por la pérdida de Cuba y Filipinas, la hispanidad también era una estrategia económica para ampliar, crear y consolidar mercados.

La pasión castiza del mundo ibérico legitimó el conservadurismo de las múltiples derechas latinoamericanas. Retóricas como el nacionalismo católico, la preponderancia del Norte Ibérico, la distinción entre la «España de los Toros» y la «España de los Leones», la «España de Abajo» y la «España de Arriba»; el fundamentalismo de las sociedades jerárquicas y orgánicas, el corporativismo, cooperativismo y mutualismo; la familia; y la subordinación de lo político a lo religioso, constituyeron una antropología de lo español. Una hispanidad castiza que sobredimensiona el siglo XVI ibérico, así como el pensamiento escolástico, humanista, personalista y tradicionalista. Una España católica que persiste en crear la alternativa Contrarreformista que cancele varias conquistas de la modernidad (socialismo, liberalismo, capitalismo y democracia). La derecha en América Latina trata de emular lo más puro español.

Con normalidad se piensa que emplear las dimensiones de izquierda; pero, sobre todo, de derecha, conlleva una descalificación, inclusive una ofensa. No obstante, la característica del Eje Izquierda-Derecha implica una condición necesaria de ubicación política. Experimentos como la «brújula política» o la metodología agonística de Chantal Mouffe (2007), pretenden establecer un diálogo honesto para definir la posición política auténtica y eliminar los subterfugios semánticos.

Para Pedro Carlos González Cuevas (2005), la esquematización derechas-izquierdas debe interpretarse como un elemento necesario del debate democrático. Más allá de una descalificación, el uso de este esquema permite equiparar los conjuntos de valores desde los cuales los actores políticos han interpretado su realidad y justifican sus acciones. La referencia a Chantal Mouffe y su ejercicio agonístico da luz acerca de la manera dialéctica en que la democracia se alimenta. El franquismo español ha tratado de distinguirse de los nacionalismos europeos que provocaron el caos del siglo XX en su primera mitad. Sin embargo, y aquí radica la importancia del esquema 
derecha-izquierda, dicha exclusión es una forma de evadir la responsabilidad que corresponde a una de las dictaduras católicas.

Como parte esencial de la hispanidad, el catolicismo español pretendió mantenerse como la medida de las cosas en América Latina; pero esto ya no funciona. La modernidad es holística y cada sociedad ha seguido la trayectoria que las circunstancias imponen. Cuando se piensa en la modernidad de México, igualmente, se hace necesario contemplar desde dónde se enfoca esta anhelada modernización. No hay modernidad, por supuesto. Hay modernidades y eso quiere decir que esta avanza, paso a paso, según las características de cada sociedad. Si México y América Latina se ciñen a las condiciones que la hispanidad afirma, entonces, encontraremos varios rezagos y oportunidades perdidas.

Si la hispanidad dejara de ser pensada como una hipoteca por los grupos casticistas y conservadores, podría emplearse como un regalo de riqueza compartida, suficiente y generosa. Entonces sí, imborrable. Lo grave de no reconocer esta condición implica el que ciertas actitudes fundamentalistas e intolerantes se vayan desarrollando y se consideren legítimas, liberales e incluso democráticas.

Roger Bartra (2009) afirmó que es necesario tener una izquierda y derecha modernas. Para ello, la derecha debe comprender cuáles de sus tradiciones tienen que ser desplazadas. La hispanidad no es el casticismo pero, los casticistas pretenden apropiarse de la hispanidad. Américo Castro (1954) afirmaba que España era judía, musulmana, cristiana y, también, indígena. El mérito de España fue crear las condiciones para que estos elementos convergieran. La hispanidad castiza debe dejar de ser la característica de una condición retrógrada, reaccionaria y conservadora. Esta es una gran prioridad por atender. Hay muchas maneras de ejercer la hispanidad. Algunos personajes, sobre todo en Norteamérica, observan la cuestión desde un enfoque comunitario más que anglosajón. Es decir, ellos se consideran como una comunidad de vida sólo con los vínculos del idioma y ciertos convencionalismos sociales. Se diferencian así dentro del país en que se encuentran (Stavans y Jaksic, 2011).

En el México actual la segregación de grupos por razón de color de piel, de origen y grado de mestizaje sigue dando cuenta de la estratificación social ¿Es el hispanismo una idea que fomenta el racismo? No necesariamente; pero ha servido como eje para la exclusión y el posicionamiento de ciertos personajes. En el caso mexicano no ha acelerado la multiculturalidad, es excluyente y concede una situación de privilegio a los criollos y peninsulares, como en la época colonial. Hasta hoy puede apreciarse en México como uno de los peores exclusivismos usado por la clase dominante.

\section{Gobiernos posrevolucionarios. Conflicto de identidades}

En la sociedad finisecular mexicana del siglo XIX es importante destacar el racismo y clasismo predominante. La presión social no sólo era ejercida por las clases privilegiadas hacia los de abajo sino también entre la propia aristocracia y la oligarquía. La perspectiva europea de las clases dominantes era desplegada sin piedad, sardónicamente, sobre las poblaciones indígenas y mestizas. No obstante que México ha cambiado desde entonces, el sutil racismo y xenofobia se mantienen como una tara cultural que propone inventar mitos respecto del origen y futuro del país.

La búsqueda o construcción de la identidad mexicana comienza antes de la revolución, pero subsiste una gran diferencia y contraste entre las costumbres de las clases humildes y las elites; así como entre la población del campo y de la ciudad. Hubo varios proyectos nacionalistas y, como en cada descubrimiento autóctono, se dieron experiencias desafortunadas por decir lo menos. Las 
múltiples caras indígenas y las castas mestizas-criollas arrojan una realidad multicultural que difícilmente se pueden congregar en lo que se denomina una nación. Las generaciones porfiristas tienen una perspectiva europea, mientras las estirpes postporfiristas tratan de ser realistas con México, se hacen nacionalistas, contemporáneos, quizá mexicanos. Sin embargo, México es un conglomerado de naciones y repúblicas, de sociedades complejas con diferentes velocidades históricas y acuerdos volátiles: ¿Serán éstas las razones de su ingobernabilidad?

En los primeros años de los gobiernos posrevolucionarios (1917-1930) se generó una modernización autoritaria que se hizo radical. El conflicto entre el Estado Mexicano y la Iglesia Católica se planteó de nuevo. El anticlericalismo constitucionalista provocó que los contingentes sociales de católicos que ya habían demostrado su fuerza y organización en los estertores del porfiriato, decidieran convocar a una Cristiada contra el gobierno del país.

De 1926 a 1929, mientras los gobiernos posrevolucionarios se volcaron en un intento secularizador, grupos católicos protagonizaron una defensa de la fe que dio ejemplo en el mundo. El saldo de la batalla fue la consolidación del Partido Acción Nacional, que funge como crisol de las múltiples derechas mexicanas y la inserción del catolicismo integral intransigente en la clase política y económica del país. Al final, el pacto entre la derecha secular y religiosa generó un modus vivendi donde los anhelos de la revolución mexicana se extraviaron y se configuró una modernidad conservadora con débiles aromas liberales. La derecha mexicana que, desde entonces, comparte el poder con los civiles que institucionalizaron la revolución, se proyecta en una propuesta hispanista castiza que no termina de asimilar la modernidad occidental con todas sus propuestas. Ahí, uno de los principales pensadores, está representado por Manuel Gómez Morín.

\section{Teoría fundamentada}

Manuel Gómez Morín constituyó uno de los principales artífices de la hispanidad, que bajo otros personajes tomó la forma de distintas relaciones entre América y España, hasta llegar a una verdadera hispanofilia. España se vuelve el parámetro que puede guiar la modernización mexicana, y la madre dolorosa que protege y orienta. No obstante, siguiendo la propuesta de Solange Alberro, aun cuando el Criollo deja de ser un Gachupín, la nostalgia de la identidad española es capaz de provocar radicalismos. En España, la marcha de la evolución política era determinada por la Iglesia Católica; por eso, es necesario comprender el proceso de construcción de las criptoderechas en México, considerando el catolicismo como elemento esencial de la hispanidad.

El acercamiento de Manuel Gómez Morín con la hispanidad fue paulatino, de forma cotidiana en su formación académica, en el ejercicio de la profesión y en los círculos sociales que frecuentaba. Al menos podemos señalar cinco fuentes en las que abreva:

1. La formación intelectual en el Ateneo de la Juventud

2. La militancia católica en las estructuras reservadas de la alta clerecía

3. La asesoría legal de empresas españolas que demandaban indemnización por la revolución mexicana

4. El acercamiento a la tecnocracia financiera

5. La proximidad al conservadurismo autoritario mediante el conocimiento del primorriverismo

6. A continuación se explora en cada una de ellas. 
La formación intelectual en el Ateneo de la Juventud. El apego que tenían los jóvenes ateneístas por el vitalismo, el intuicionismo, el romanticismo y los clásicos griegos, fue mostrándole alternativas a la dictadura progresista del General Porfirio Díaz que le generaban una simpatía por la revolución mexicana en su faceta maderista. Frente al positivismo emergieron las humanidades, y con ellas la radicalización de los proyectos nacionalistas.

El final de la dictadura progresista del General Porfirio Díaz sufría los mismos problemas que la monarquía de Alfonso XIII. La situación de México se agravaba por la edad del dictador y no obstante el monarca español era mucho más joven, ambos se enfrentaban al estigma de un régimen decadente, disfuncional e incompetente, donde el liberalismo actuaba de forma irresponsable y el conservadurismo insistía en una graduación de los cambios. Así como en España se acusaba a la monarquía de haber tolerado el liberalismo y las filosofías cientificistas en contra de la identidad nacional, en México se hacía la misma llamada de atención al pofiriato. Una fuerte demanda conservadora, por ejemplo, la considera John Womack al describir el fenómeno zapatista. Las élites, los militares, los estudiantes, los hacendados y clases medias, proletarias, no tardaron en desplegar la misma acusación que los campesinos. Pocos grupos atinaron a establecer las medidas y diagnósticos pertinentes. Como se ha dicho antes, la cultura política latina es una limitante porque el tamiz consservador se impone en cualquier transición.

José Vasconcelos, Pedro Henríquez Ureña, Alfonso Reyes y Antonio Caso generan una influencia hispanista en Manuel Gómez Morín apenas perceptible durante sus años como estudiante y espectador del Ateneo, la Sociedad de Conferencias, etc., pero no menos importante a la postre. De hecho, esta influencia tradicionalista puede observarse en otros miembros de los Siete Sabios que más tarde se colocarían en las antípodas de Manuel Gómez Morín. El conjunto de estas ideas ha dado en llamarse Humanismo y constituye una oposición intelectual al positivismo y cientificismo del porfiriato. Al tiempo, cada personaje incorporaría los elementos culturales y políticos de su contexto para incrementar o disminuir esta influencia ateneísta tan importante y significativa. Gómez Morín, como la mayor parte de los cuatro grandes ateneístas, decanta en el hispanismo casticista y sus circunstancias le acercan incluso al nacionalismo católico del falangismo español.

Enrique Krauze (2000) sostiene que la política fue responsable de la polarización, extravío y confrontación de estos personajes que abrevaron del humanismo y de un hispanoamericanismo que hasta el día de hoy se presenta como una alternativa para la identidad y desarrollo político de Iberoamérica.

La militancia católica en las estructuras reservadas de la alta clerecía. Durante el porfiriato el Partido Católico Nacional mostró el poder de las masas católicas; empero, fue derrotado por las circunstancias y el desdén burgués de sus dirigentes. Tiempo después, en 1929, la campaña vasconcelista constituyó un primer ensayo de la coalición de derechas logrando reunir liderazgos conservadores de diverso tipo: revolucionarios, religiosos y modernizadores. De ahí la insistencia de Gómez Morín a Vasconcelos para fundar un partido político de vanguardia (Arriola, 2008).

En el vasconcelismo fue fundamental la participación de los jóvenes universitarios, quienes ya habían tenido una notable actuación en el maderismo, el combate al bonapartismo sonorense y la revolución cristera. Diez años después, esos mismos universitarios, acompañados de nuevas generaciones, acudieron a la organización de las derechas en una nueva familia: el Partido Acción Nacional; aunque detrás de esta vocación cívica es importante reconocer la enorme influencia que tenían las sociedades católicas, tanto abiertas como reservadas, en los espacios 
educativos del nivel superior. La Unión Nacional de Estudiantes Católicos (UNEC) constituye el caso paradigmático de este tipo de asociaciones y su estudio ha permitido explicar tanto el origen como las estrategias y los fines últimos del liderazgo político y social de varios personajes mexicanos (Aspe, 2008).

La influencia religiosa en el actuar político de Gómez Morín generó un interesante debate entre Soledad Loaeza y Alonso Lujambio (2009). Mientras éste lo califica como un hombre laico y liberal, desde la óptica académica, hubo alianzas convenientes entre Manuel Gómez Morín y grupos de estudiantes católicos durante su período como rector en la UNAM y, posteriormente, en la conformación del PAN. Sin embargo, es necesario entender que esto va más allá de una alianza conveniente; no es ni coincidencia ni pragmatismo. Los claroscuros de la militancia católica del personaje confirman su hipoteca católica, que se expresa en su paso por la rectoría de la Universidad Nacional y en la fundación del PAN. Otros estudiosos, como Rodríguez Araujo (2014), evidencian que en muchos países europeos y latinoamericanos se desarrollaban partidos confesionales de derecha en circunstancias y con protagonistas semejantes.

La Compañía de Jesús fundó organizaciones para los diferentes extremos sociales del país con el propósito de unirlos como una gran fuerza, tal fue la intención del Partido Católico Nacional, aunque el esquema de solidaridad jesuita no se consolidó debido a las diferencias sociales. Hay que decir, sin embargo, que fueron los españoles y criollos quienes a lo largo de la colonia y durante los primeros años de la independencia, mantuvieron discursos y actitudes que hacían patente su diferenciación respecto de los demás. La vigencia de las ideas que, por ejemplo, sostenía Daniel Cosío Villegas (1947) respecto de la Iglesia Católica y el PAN tienen una actualidad que sorprende. Habrá que observar la forma en que la historia de cada país implica una lucha contra poderes fácticos como los del Estado Vaticano, en una lucha constante en la cual la fe religiosa mina la lealtad que los Estados intentan generar entre sus ciudadanos.

Al analizar la biografía del personaje en cuestión, se puede entender que su vida estuvo al servicio de la burocracia eclesiástica aún antes de tiempo. De ahí la importancia de resaltar el concepto de hispanidad que postula en su texto España Fiel. La predisposición católica se deja entrever en la trayectoria escolar del personaje así como en la cercanía a personalidades representativas del conservadurismo en diferentes ámbitos.

En la década que va de 1929 a 1939 la Universidad se vuelve el instrumento de organización, alianza y proyección de esa coalición de derechas que con el tiempo sería el PAN. La versión de este nuevo partido para católicos ya no tomaba como estrategia las bases sociales católicas sino el liderazgo y espíritu de servicio de las minorías excelentes, condición que homologaba el contexto mexicano con el español, donde se exigía a estas élites intelectuales, militares, políticas, etc., el sacrificio para organizar Iberoamérica bajo la bandera de la Hispanidad. Liderazgo y sacrificio al que tenían que sujetarse los ciudadanos y las masas porque en ello iba también su salvación. Por esta razón no es lejano el corporativismo orgánico que Gómez Morín aprecia en la España de Primo de Rivera con aquel que propone la Asociación Católica de la Juventud Mexicana (ACJM), la UNEC y, más tarde, la Unión Nacional Sinarquista.

En el ámbito universitario, un elemento significativo es su nexo con la UNEC y su antecedente formal, la Confederación Nacional de Estudiantes Católicos, desde la temprana época en que las organizaciones de estudiantes católicos son determinantes para el actuar de las instituciones educativas, particularmente con el sacerdote Ramón Martínez Silva. No obstante la inspiración belga en las organizaciones de jóvenes cristianos, se proyectaba en ellas un profundo pensamiento hispanista. 
Aunque formalmente la UNEC se distanciaba del conflicto religioso en México, sus antecedentes se encuentran en la intelligentsia que inspiró a los Cristeros sin Rifle en la mayor parte de las ciudades mexicanas. La Guerra Cristera en México fue una cruzada contra el comunismo ateo. Hay que entender que la Iglesia Católica vivía un Viernes Negro que, desde su mentalidad, racionalizaba una crisis de la catolicidad como consecuencia del avance que tenía la modernidad. Gómez Morín no tiene ideas manifiestas sobre el conflicto religioso y la revolución cristera; sin embargo, la situación de persecución, violencia y revueltas que se extendían por varios espacios del país, le obligaban a sentirlo como un presidio. El catolicismo es un tatuaje que llevará siempre. Con el tiempo, Manuel Gómez Morín atendería positivamente el actuar de los cristeros en la confrontación con el Estado Mexicano:

JW: [...] al entrar Calles, y al ver que un tipo de socialismo iba enfrentándose a la nación, que no era religioso, que quería basar el desarrollo del país en el ejido y en una vida más conmunal, entonces vino esa quiebra definitiva entre los valores católicos y el Estado. ¿Puede comentar sobre eso?

MGM: [...] El hecho de que Calles sintiera que podía formarse un grupo católico importante fue lo que lo obligó a extremas ciertas medidas que él sabía que motivarían una reacción violenta [...] Creo que él mismo después, y aun durante los acontecimientos, se lamentaba de que se cometieran los excesos que se cometían. Pero ya estaba lanzada la facción. Se inició la persecución terrible, y la reacción de los cristeros fue natural, era obvia

JW: ¿Y los cristeros? [...] ¿Y cuál es su juicio de usted hoy sobre el movimiento de entonces?

MGM: Maravilloso respecto de los que estaban dentro de él, sacrificándose abnegadamente; tal vez adverso para los que lo dirigían desde arriba y que no supieron o no lograron nunca darle sentido (Wilkie y Monzón, 1978, pp. 23-58).

Los estudiosos del catolicismo intransigente señalan a la UNEC como uno de los elementos más representativos del fundamentalismo religioso. Esta asociación, determinante para que Gómez Morín ascendiera a la rectoría de la Universidad, fue siempre representativa de la geopolítica vaticana (Gonzáles, 2003). Gran parte de su actuación obedecía a los intereses de la Santa Sede más que los intereses de los católicos mexicanos.

Por otra parte, los vínculos entre Manuel Gómez Morín y las sociedades reservadas de la alta jerarquía católica todavía no se manifiestan abiertamente; empero, son conocidas las evidencias -a destiempo- de su cercanía con La Base, organización vinculada a la fundación de la Unión Nacional Sinarquista en 1937, tal como como lo han reconocido Salvador Abascal (Gonzáles, 2003, p. 53) e Yves Solís (2010).

En medio de la crisis por la Autonomía de la Universidad, fueron los estudiantes católicos los que garantizaron la estabilidad, y en general fueron los padres de familia católicos quienes cuestionaron las reformas al artículo tercero constitucional. Estas movilizaciones, sin embargo, tuvieron siempre un soporte invisible, sociedades reservadas encargadas de estructurar y movilizar, como en el caso de la Unión Nacional Sinarquista y su relación con la Legión y la Base. Probablemente ahí se vinculó también con la estructura religiosa y militante que lo fue orientando hacia el hispanismo.

Un dato curioso que cobra relevancia es el hecho que de todos los documentos que tuve la oportunidad de consultar durante mis dos estancias de investigación en los Archivos Secretos Vaticanos, solamente me encontré con un documento alterado, un documento relacionado con la petición de crear un partido católico, un partido cuyas siglas cambiadas eran PAM pero cuyo 
programa y fundadores fueron claramente establecidos, el Partido Acción Nacional de Gómez Morín y Gónzalez Luna, creado con la venia del Comité Episcopal Mexicano [...]. El apoyo al PAM provocó la inconformidad de Pascual Díaz con el Comité [...] (Solís, 2010, pp. 47-48).

El Sinarquismo fue uno de los movimientos hermanados de Acción Nacional. Al tiempo, esta organización evolucionaría en organizaciones como el Movimiento Universitario de Renovadora Orientación (MURO) y el Yunque, lo que deja ver la mentalidad que inspiraba su actuación original y el tipo de hipoteca impuesta a Manuel Gómez Morín en su momento. Es importante señalar, por ejemplo, que personajes como Emilio Portes Gil señalaban que los Caballeros de Colón y el Opus Dei tenían infiltradas y secuestradas a las instituciones de educación superior en México desde muchos años antes. El PAN y México mantienen una hipoteca religiosa-como sugiere Soledad Loaeza-, aun cuando el país ha tratado de emanciparse en varias ocasiones.

Entre las instituciones mejor organizadas de la Iglesia Católica figura el llamado Opus Dei, que nació en España, fundado por Josemaría Escrivá [...]. Esta institución actúa de modo claro y abierto [...] tiene como mira la conquista de la juventud que asiste a las reuniones, centros de cultura y, quienes actúan generalmente son jóvenes cultos de aspecto agradable, y llevan una vida social activa.

En la Universidad Nacional Autónoma de México, en las secretarías de Estado y en muchas oficinas públicas, existen connotados miembros del Opus Dei, quienes para entrar al país lo hacen como profesores de universidades y altos centros de cultura [...] (Portes Gil, 1964, pp. 644).

La esquina de la catolicidad es España. El conflicto entre los hispanistas y los gobiernos de Plutarco Elías Calles y de Lázaro Cárdenas está relacionado con la propuesta, sobre todo, de estos últimos grupos de un fenómeno que extraviaba y hacía perder el enorme bagaje histórico con que cuenta México en su experiencia colonial. Lo cierto es que, de pronto, los gobiernos del nacionalismo revolucionario pretendían hacer tabula rasa para construir el mundo que la utopía social los llamaba. De cualquier modo, es humanamente imposible desprenderse de España.

Debe resaltarse que la diferencia entre Fe y Burocracia Eclesial es importante. Muchos revolucionarios mexicanos eran hombres de convicciones religiosas profundas, empero, no estaban dispuestos a ceder una parte de la soberanía nacional a los grupos políticos de la Burocracia Eclesial que, la mayor parte de las veces, actúa siempre con utilitarismo y menos con fe con sentido de la oportunidad política y sin humanismo.

De ahí que Calles, por ejemplo, haya pretendido la formación de una Iglesia Católica Mexicana que emancipara el catolicismo en nuestro país. El problema es la organización política del catolicismo, no la fe. La confrontación siempre se genera entre la Santa Sede y el Estado mexicano.

El hispanismo promueve la subordinación de los Estados Nacionales a la Santa Sede. El problema con la Hispanidad implica la no distinción entre la fe y la organización, gravedad que ha orientado a los países hispanoamericanos hacia el clerofascismo. Espacio donde la discusión verdadera por la secularización resulta inútil.

La asesoría legal de empresas españolas que demandaban indemnización por la guerra civil mexicana. La cercanía con la comunidad española permite a Manuel Gómez Morín la supervivencia, y al mismo tiempo desarrolla en él una simiente contrarrevolucionaria. En su biografía destacan algunos datos que pueden revelar una relación estrecha con la colonia española en México desde inicios de la segunda década del siglo XX. Uno de estos nexos inicia con la 
expulsión de españoles del noroeste del país por los constitucionalistas, particularmente por el General Francisco Villa en Chihuahua.

Sobre este particular, tanto Alfonso XIII como el intelectual Ramiro de Maeztu enviaron sendas notas de crítica al Jefe constitucionalista, Venustiano Carranza, y expusieron en Europa y en España la situación de persecución y asesinato a que estaban sometidos los peninsulares en México. Esta información se publicaba de manera constante en diversas revistas españolas y favoreció la figura de Victoriano Huerta, siendo España uno de los primeros países en reconocer su gobierno (Ruíz de Gordejuela, 2012; Sevilla, 2005 y Deras, 2015).

Para justificar estas acciones en contra de la colonia española, el carrancismo argumentaba el apoyo de ésta al Golpe de Estado contra el Presidente Francisco I. Madero, ${ }^{2}$, así como la simpatía mostrada hacia el usurpador Victoriano Huerta. De estos señalamientos tampoco escaparía la Iglesia Católica que, en una proporción mayor, guardaría una confrontación permanente hacia el régimen emanado de la Revolución Mexicana. De ahí que los carrancistas, y personalmente el General. Francisco Villa tomara medidas en contra de ambos actores.

Si bien los levantamientos no terminaron con el aparato productivo del país, algunos estados como Chihuahua sufrieron duramente los embates de la lucha armada. Además, dentro de ese estado los ciudadanos españoles fueron expulsados y sus negocios fueron ocupados por el ejército de Pancho Villa. Manuel Gómez Morín, hijo de padre español con negocios en Chihuahua, conocía a dicha comunidad y su padrino, Benito Martínez, tuvo una participación importante en diversas empresas comandadas por españoles (...) Fue a través de Martínez que, a principios de la década de los veinte, Gómez Morín recibió diversas peticiones de empresarios españoles para que los asesorara en torno a cómo obtener, ante la recién creada Comisión Nacional de Reclamaciones (1919), indemnización por daños causados por la Revolución. Desde 1920, Gómez Morín fungió como apoderado para conducir trámites legales en la Ciudad de México de varias empresas (...) (Recio, 2017, pp. 121-122).

Décadas después, Gómez Morín argumentaría, de modo firme, el apoyo que determinados sectores brindaron a Victoriano Huerta. En su opinión, fue el sentido de supervivencia, la aspiración al orden y estabilidad lo que impulsó el desapego del movimiento social armado y la proximidad al militar que prometía reinsertar la paz en un país donde la violencia parece eterna.

JW. Pero, referente a Huerta, los historiadores dicen que el clero y los conservadores católicos apoyaron a Huerta, y que, después de eso, surgió la división entre los católicos y los revolucionarios.

MGM: Sí, este es un buen pretexto político. Es posible que muchos de los que apoyaron a Huerta fueran católicos. Pero no lo apoyaron en tanto que católicos; lo apoyaron porque estaban en un grupo social diferente, porque habían sufrido con la época violenta de la Revolución, por otros motivos; porque estaban inconformes con el caudillismo y el espíritu faccioso, porque no admitían la perpetuación de la lucha como pretexto de aprovechamientos o de apetitos personales o como encubrimiento de ineptitud para plantear y resolver los problemas de México. No creo que se haya definido históricamente ese punto (Wilkie y Monzón, 1978, p. 22).

\footnotetext{
2 La Iglesia Católica, como organización, mantiene un poder fáctico y de legitimación que difícilmente se puede contradecir. La Burocracia Eclesial es representativa de un Estado que difícilmente puede ser combatido y exhibido. El propio Francisco I. Madero, quien elabora uno de los diagnósticos más vigentes de la situación social, económica y política del país. Al tiempo, fue rechazado por los católicos y el partido político que, para sustituir a la dictadura pretoriana clerical que bien les había servido, habían inventado. El resto de las propuestas políticas fueron descartadas por el clericalismo. Los movimientos y tendencias más representativas de la revolución mexicana fueron calificados de socialistas, comunistas, liberales, anarquistas y ateos. Con el tiempo, incluso la Iglesia Católica se daría espacio para enfrentar el gobierno del General Plutarco Elías Calles. Contradicción que Hugh Campbell (1976) enuncia como el enfrentamiento de la derecha religiosa y la derecha radical.
} 
Una vez concluida la revolución mexicana, uno de los primeros empleos jurídicos del joven litigante fue la promoción legal de indemnizaciones para los españoles expulsados del norte de México, inclusive defendió empresas de Columbus que habían sido atacadas por el General Francisco Villa. Su apego a los grupos familiares, comunidades y empresarios españoles así como la influencia que tiene el pensamiento religioso en su persona, permite observarlo prácticamente como un miembro más de la comunidad española, enterado del ambiente político español y en una estrecha relación con los elementos de la hispanidad, mismos que, le aseguraban tanto lazos de solidaridad como posibilidades de ascenso social.

La participación de su padrino, Benito Martínez, en las empresas españolas afectadas por la revolución mexicana y, sobre todo, por el General Francisco Villa, puede orientar una preferencia social por las comunidades hispánicas y sus intereses económicos, situación que al tiempo que lo vincularía con los grupos económicos más poderosos y representativos de la ultraderecha mexicana, por ejemplo el Grupo Monterrey, también puede ser un indicador de la forma en que construye su plataforma política.

El acercamiento a la tecnocracia financiera. Manuel Gómez Morín colaboró con los primeros gobiernos revolucionarios en una época en que la larga fila de generales bonapartistas disputaba el poder a balazos, no con capacidad política.

Después de la frustrada ilustración positivista, las reacciones nacionalistas tomaron todos los rumbos. Con todo y la revolución mexicana, las contradicciones raciales de un país como el nuestro no se acabaron. El triunfo constitucionalista sobre Emiliano Zapata y Francisco Villa representa el dominio no sólo de la burguesía norteña sino la exclusión del México indígena, humilde y sureño.

La ilusión que adquiere el proyecto revolucionario se torna una experiencia traumática al constituirse un gobierno formal. Sus extravíos y fatalidades precisaban de un retorno, una corrección del rumbo; quizá una vuelta al origen.

En 1921, siendo presidente el General Álvaro Obregón, Manuel Gómez Morín, sin abandonar su despacho jurídico, se incorpora a las tareas administrativas, primero como Oficial Mayor de la Secretaría de Hacienda y en ese mismo año como subsecretario de la institución y como agente financiero de México en Nueva York. Durante su estancia en esa ciudad asiste a cursos de Ciencias políticas en la Universidad de Columbia.

A su regreso, en 1922, decide regresar a sus tareas en la Universidad Nacional y para 1925 considera volver de manera definitiva a las tareas como abogado. Sin embargo, acepta la invitación a incorporarse al Departamento de Hacienda de la Comisión Monetaria y a colaborar en la creación de dos instituciones financieras: el Banco de México, del que será Presidente hasta 1929, y el Banco de Crédito Agrícola, promesa de la revolución, que terminó financiando créditos para altos funcionarios del gobierno que nunca fueron pagados.

El desencanto con las políticas de los gobiernos posrevolucionarios, fundamentalmente con las propuestas nacionalistas que hacían énfasis en la mestizofilia y el indigenismo, irrumpieron en el contraste de sus creencias; o bien, las hicieron afirmarse. El Bonapartismo que se concentró en los militares y personajes socialistas, lo obligó a marginarse y observar el extravío que tomaba el gobierno de la revolución mexicana. En 1927 emprende el viaje a España, que durará aproximadamente un año y que resultará revitalizante por la cercanía a un país en expansión económica (Gómez, 1996). Esa estancia se acompaña del autoexilio de otro importante creador 
de instituciones financieras, quien ocupa la embajada de México en Francia, Alberto J. Pani, con quien Gómez Morín comparte ideas.

De forma paralela, la búsqueda del poder por parte de las facciones conservadoras, clericales y de derecha, encontraría en Manuel Gómez Morín un asidero y un espacio de emergencia. $\mathrm{Su}$ experiencia, financiera y legislativa, su capacidad para proyectar el desarrollo nacional, encuentran más coincidencias en España que en México. De ahí que, desde su colaboración en el gobierno callista, comenzara a articular un proyecto que avanzaría con la agregación de tecnócratas, clericales, fascistas, conservadores, monarquistas y nacionalistas que en 1939 se presentaría como alternativa frente al proyecto emanado de la revolución. Su entrevista con José Calvo Sotelo lo imbuye en el maurismo, ${ }^{3}$, dirigismo tecnocrático o burocratismo autoritario, considerando que Calvo Sotelo es un importante artífice de instituciones financieras durante el primorriverismo.

La proximidad al conservadurismo autoritario mediante el conocimiento del primorriverismo. La crisis de la monarquía, la restauración y la identidad de España, motivaron el surgimiento de varias corrientes de pensamiento que procuraban encontrar un nuevo sentido patriótico a finales del s. XIX. El orden social se encontró frente al dilema de la modernidad espontánea-liberal o la dirigida-conservadora (Badie y Hermet, 1993).

Previo a la Dictadura Primorriverista, es necesario destacar el período crítico del Restauracionismo durante el cual las ideologías enemigas del catolicismo -el canovismo, socialismo, republicanismo, liberalismo- son responsabilizadas del caos imperante. En estas condiciones, la dictadura logró hacer coincidir múltiples derechas que pretendieron encontrar cauces a la crisis española, de entre las cuales resaltan el conservadurismo burocrático, nacionalismo católico, carlismo, dirigismo tecnocrático y el tradicionalismo. Miguel Primo de Rivera acometió formar un Partido de Estado con las múltiples derechas que correspondían a su entorno; sin embargo, los poderes fácticos de la época así como la incapacidad política de Alfonso XIII, provocaron un nudo de circunstancias que culminarían con el fin del progresismo autoritario.

En España, la mayor parte de los movimientos ideológicos, políticos y sociales fluyeron a la zaga de la Iglesia Católica; la influencia del catolicismo guiaba y controlaba las decisiones de políticos, intelectuales y profesionistas, lo que generó una velocidad histórica rezagada en comparación a Europa.

Las nuevas tendencias políticas, pero, sobre todo, la modernidad, generaban un temor singular en el país en torno a la mejor manera de insertarse en el concierto internacional salvaguardando al mismo tiempo la identidad y la tradición. La hispanidad, entonces, cobra su sentido político, afirmando la raza, el idioma, la tradición, y sobre todo la religión, como elementos capaces de afianzar una comunidad con América y al mismo tiempo contener los nacionalismos periféricos del norte.

No obstante que Primo de Rivera impulsa la estrategia geopolítica de la hispanidad, desde el centenario de las independencias americanas estas ideas respecto a la unidad espiritual hispánica ya se encontraban circulando en los espacios económicos, culturales y religiosos de América Latina. Durante el porfiriato y en los primeros años de los gobiernos posrevolucionarios, los intelectuales criticaron los intentos nacionalistas que pretendían separarse del lazo español. La

\footnotetext{
3 Antonio Maura, presidente del gobierno español en varias ocasiones, es el representante de una corriente tecnocrática influenciada por el pensador francés Charles Maurras. Maura propugnaba también un gobierno de minorías excelentes, técnicas, católicas que llevaran a cabo «una revolución desde arriba». El maurismo será fundamental en el posterior desarrollo de la tecnocracia franquista.
} 
formación académica de Gómez Morín no fue ajena a estas circunstancias, a las cuales retornó después de su frustrante colaboración con los gobiernos de Álvaro Obregón y Plutarco Elías Calles. Gómez Morín buscaba una alternativa frente a lo que ocurría en México, y en España encontró que siempre había estado ahí.

En el período de mayor vehemencia de la guerra cristera (1927-1928), Gómez Morín no se encontraba en México; había viajado a España. Este aspecto de su vida es fundamental para entender ideológicamente al partido que posteriormente fundaría [...]. Una de las principales estudiosas del nacimiento del PAN y del papel desempeñado por sus fundadores documenta la influencia y la admiración de Gómez Morín por el gobierno español encabezado por el general Miguel Primo de Rivera [...] el modelo admirado por Gómez Morín fue el creado en 1925, cuando el directorio militar dio paso a un directorio civil [...] y se creó una institución de representación corporativa basada en la doctrina orgánica denominada Asamblea Nacional (1927) que se integraría con gremios de trabajadores, la Iglesia católica, representaciones patronales y las universidades.

La ideología oficial del régimen de Primo de Rivera era el hispanismo; esa fue la primera herencia intelectual obtenida por Gómez Morín [...] (Fernández de Santillán, 2016, pp. 39-54).

La capacidad técnica de Gómez Morín había sido incomprendida por los gobiernos posrevolucionarios, los cuales recurrían a proyectos políticos que contrastaban con la hispanidad y el catolicismo. En España, frente a circunstancias semejantes, la dictadura primorriverista estableció una coalición de derechas donde la hispanidad, la catolicidad y el dirigismo tecnocrático, así como el corporativismo tradicionalista, embonaban de modo adecuado, lo que pudo antojarse pertinente para la situación mexicana.

El viaje a España puede constituirse, entonces, como un círculo hermenéutico en el cual la dictadura de Miguel Primo de Rivera permite a Manuel Gómez Morín la convergencia entre los principios católicos y tradicionales, y el sentido técnico económico recién adquirido a su paso por los gobiernos posrevolucionarios. La convivencia con José Calvo Sotelo -seguidor Antonio Maura-, que vaticinaba la entrada triunfante de España en el mundo, presenta proyectos semejantes; en este sentido, el encuentro con España tiene aspecto de cruzada civilizatoria.

A diferencia del comunismo ruso o del capitalismo anglosajón, el modelo español de la dictadura primorriverista no era considerado como una influencia ajena o indeseable a la experiencia mexicana. Después de todo, en la visión hispanista que Gómez Morín compartía, España y sus antiguas posesiones formaban parte de una misma familia espiritual y cultural unida por la lengua española y el catolicismo (Calderón, 2015).

La hispanidad, entendida de esta manera, como una estrategia de unidad y de control, que inicia desde el siglo XIX, se extendió hasta el régimen franquista, alimentando distintas tendencias de derecha, identificadas con políticos o intelectuales simpatizantes del nacionalismo católico como Antonio Maura (Reformismo Conservador), Charles Maurras, José Antonio Calvo Sotelo, Miguel Primo de Rivera, Rafael Altamira, José María Pemán, Ramiro de Maeztu, Juan Vázquez de Mella, Félix Sardá i Salvany, Zacarías de Vizcarra, y otros.

El hispanismo de Gómez Morín se sustenta en sus filiaciones políticas con grupos hispanistas y en importantes nexos desarrollados con la falange española a través del Consejo de la Hispanidad [...] justificó el golpe militar de Primo de Rivera [...] porque, además de reactivar la economía española, lejos de provocar caos e incertidumbre jurídica, consideraba que el liberalismo constitucional que se violentó no tenía ninguna legitimidad debido a su alejamiento de las raíces hispánicas [...] el primer proyecto de Acción Nacional sostenía la viabilidad de un 
Estado orgánico y corporativo "acorde con nuestra hispanidad", que habría de ser impulsado por asociaciones construidas de manera voluntaria y no por coerción e imposición del gobierno. Esto en clara crítica al modelo corporativo adoptado por el general Lázaro Cárdenas para organizar a los trabajadores y campesinos. Por ese motivo, el corporativismo hispanista de Gómez Morín criticaba al corporativismo oficial de los revolucionarios [...] (Fernández de Santillán, 2016, pp. 42-43)

El aprecio de Gómez Morín por el desarrollismo primorriverista es evidente; España Fiel muestra una descripción del norte vinculado a la industria y la agricultura tecnificada, en tanto que la comparación entre las regiones menos desarrolladas de España con México es recurrente, pues observa en esos espacios las posibilidades que brinda el modelo implementado en el norte español.

\section{Análisis de contenido}

España Fiel muestra una peculiar manera de la hispanidad castiza y católica del siglo XVI que sobrevivió en las estrategias del nacionalismo católico español hasta el Siglo XX. La forma en que fue expuesta por Manuel Gómez Morín, permitió generar acuerdos y el reclutamiento de los grupos católicos carismáticos y de las clases medias y altas, acordes con el discurso de las minorías excelentes. España Fiel señala, activa y enciende el espíritu de las minorías excelentes, la Patria del Criollo y la esencia de la catolicidad composteliana.

En este sentido, este ensayo constituye un vaso comunicante capaz de recolectar distintas formas de una relación amigable con España tanto en su versión de Madre-hija como en la de la construcción de un patrimonio común, y al mismo tiempo proyectar tales interpretaciones en la fundación del Partido Acción Nacional, en 1939.

Los primeros intentos por construir la identidad nacional desde el nacionalismo revolucionario mexicano se frustraron y, como en el caso de las civilizaciones bastardas, se generó una idealización de los padres ausentes por parte del hijo. La hispanidad constituye el remedio para los cataclismos que produjo la modernidad de los gobiernos posrevolucionarios en México; en España aparece el embrujo que responde a sus dudas y que le permite construir un modelo auténtico, verdadero, civilizatorio, humano y orgánico que atiende su ser.

La ilusión que envuelve el proyecto revolucionario se torna una experiencia traumática al constituirse un gobierno formal. Los extravíos y fatalidades precisaban de un retorno, una corrección del rumbo; una vuelta al origen. Así como Juan Nepomuceno Almonte se volvió monarquista, Manuel Gómez Morín adopta el hispanismo. España parece expiar sus pecados revolucionarios, le devuelve la sensatez y la fe. Por esa razón, es necesario atender las situaciones que incrementaron su compromiso religioso e hispanista.

Manuel Gómez Morín encuentra las virtudes hispanas en el norte, ${ }^{4}$, al que señala como elemento identificador. Dicha porción de la península ibérica se manifiesta como un baluarte de la cristiandad, la raza, el trabajo, la austeridad y la riqueza en detrimento del sur. Tácitamente, el ideal que activa la situación de redefinir el país cuando este se extravía, se materializa en los vientos del norte español.

En la época actual, las provincias más católicas de España están en Andalucía, Extremadura y Castilla; sin embargo, los monasterios son más numerosos en el Norte, provincia mística, en

\footnotetext{
4 Regiones del Norte: Galicia, Asturias, Cantabria, País Vasco, Navarra, La Rioja, Aragón, Cataluña, Madrid, Baleares y Castilla y León.
} Regiones del Sur: Castilla- La Mancha, Extremadura, Andalucía, Comunidad Valenciana, Murcia e Islas Canarias. 
consonancia con el discurso histórico en la zona durante la Edad Media (Cataluña y Galicia); en cambio, son menos numerosos en el Sur (Andalucía y Canarias).

Estas instituciones surgieron en torno a la Ruta de Santiago y como estructura de ayuda al Peregrino. Debe destacarse, históricamente, una cultura de sociedades secretas, códigos y catacumbas que influyen en la zona como artífices de la protección católica. La región Euskadi, Cataluña, Galicia y Navarra se protegen de la influencia árabe y son quienes logran la expulsión del Islam; por el contrario, la región del sur se define como multicultural, poca religión ortodoxa católica y con la mayor parte de los vicios que se atribuyen al espíritu español.

Las diferencias entre el Norte y el Sur de España se mantienen, como lo describía Gómez Morín. Ahora, como entonces, sigue siendo determinante la situación económica. Mientras en el Norte hubo un avance de la industria y los talleres corporativos, en el sur predomina la agricultura. El Norte siempre ha despuntado en términos de empleo; en el Sur el desempleo y la pobreza afectan notablemente a las personas. El campo ya no da empleo a la gente, la región ha necesitado del subsidio agrario, la economía solidaria y la emigración.

La comparación entre el Norte y el Sur de España sigue siendo odiosa. Existen intenciones de integración y conocimiento mutuos; empero, los particularismos y nacionalismos regionales insisten en que la unidad española consiste en un mito. La disputa por las autonomías e independencias sigue afirmando que existe una España que pierde y otra que gana, la que exporta y la que no, la que se confía al ladrillo y la que cuenta con industria, turismo y comercio.

Las regiones del Sur de España se caracterizan por un mayor peso de la agricultura y la construcción y menor valor de la individualidad. Al no disponer de actividades industriales, se limitan las alternativas de crecimiento económico y desarrollo.

La España del Sur es la España de la desigualdad, la que pelea por la justicia social. En el Norte hay preferencias históricas por la derecha política (Santander, Galicia, País Vasco, Asturias, etc). Las raíces profundas de los pueblos del Norte, sus fuertes estructuras en familias y clanes explican su herencia conservadora. El Norte se considera gente decente, consonantes con los poderes fácticos del mercado y el dinero. Representan los intereses financieros e industriales. Tiene una demanda nacionalista o identitaria más fuerte que el Sur.

El Sur, geográficamente, tiene un tiempo más caluroso, con más sol y menos lluvias. Eso puede ayudar a que el carácter de las personas sea más afable y abierto; no obstante, se les señalan defectos como ser menos trabajadores, fiesteros y dedicados al ocio. A los del Norte se les achaca un carácter fuerte, son reservados y menos abiertos, son considerados fríos. La disparidad entre el Norte y el Sur es amplia; la España del Norte se aleja de la del Sur, sus diferencias no sólo se mantienen, sino que tienden a aumentar.

\section{Conclusión}

Un argumento que Aquilino Duque (1984) emplea para evidenciar los problemas de España cuando la transición política coincide con una crisis de la modernidad, también se puede implementar en un sentido retroactivo: España siempre llega tarde al banquete de la historia. Las mutaciones que ocurren en la cultura occidental tienen un impacto diferente en España debido a su grado de desfase; el elemento que carga con la responsabilidad de tal situación es la Iglesia Católica. 
La Iglesia Católica era la medida del pensamiento en España, y ésta, a su vez, el paradigma de desarrollo para Gómez Morín. La forma en que Gómez Morín interpreta la realidad española es singular, su gran capacidad intelectual también está permeada por la Iglesia Católica. La preferencia por el norte de España tiene que ver con la defensa, subrepticia, de la cristiandad de catacumbas, orden y familia, y tradiciones que representa la región. En su análisis, la secularización no fue un tópico para debate, de ahí que sus propuestas, en general fueran compatibles con el catolicismo. El Estado español aparece, aun, irreductiblemente controlado por la Iglesia, sometido por la ultraderecha.

No debe olvidarse que en Iberoamérica el catolicismo ejerce una influencia notable en la mayor parte de los ámbitos cotidianos. Las consecuencias de que la Jerarquía Eclesiástica haya tenido tanto poder, generó caciquismos, burocratismos, clientelismo, corporativismo y una serie de vicios comprendidos en la política mediterránea: faccionalismos y particularismos. La hispanidad castiza subordina la política a la religión y permite que sus valores se acerquen a todos de una forma sencilla y ordinaria. El conjunto de tesis castizas que se plantean en el hispanismo llevan a destacar el sentido humano, vitalista, pero sobre todo, conservador de la política.

La comparación entre la revolución inglesa y francesa también nos ayuda a entender la justificación del conservadurismo español. En este sentido, aun cuando se identifique un elemento responsable, existen otras condiciones que también son imperantes. Mientras el espíritu francés destaca por su pasión e idealismo, el anglosajón desarrolla su habilidad utilitaria y gradual. Inglaterra necesitó sólo dos revoluciones para consolidar su modelo de gobierno; mientras tanto, Francia experimentó cuatro repúblicas que acumularon siglos hasta encontrar un modelo óptimo. Para España, el modelo a seguir fue la modernidad reaccionaria.

El conservadurismo hispánico, y el abanico de derechas que lo conforman, despliegan una riqueza discursiva cuyo propósito es aclarar y responder al conjunto de polémicas que desata la transformación política en su sentido liberal, socialista y democrático. Para el hispanismo, la reflexión sobre el contenido ideológico, social, teleológico y científico evidencia una forma sobresignificada de la política, que se vuelve - entonces - antipolítica. Su propósito es dejar a la política sin adjetivos para, con ello, conceder un sentido práctico, realista, utilitario a dicha actividad.

Si bien es cierto que Gómez Morín disminuye el peso de la hispanidad en las entrevistas que concede a James Wilkie cuando se refiere a José Vasconcelos, el Sinarquismo, el Clero y el PAN, no niega el haber buscado coincidencias con estos personajes e instituciones que siempre propugnaron la hispanidad casticista. Aunque Gómez Morín afirma que el ecumenismo es una actitud que coloca a México y España dentro de la cultura occidental, ciertamente olvida considerar que la hispanidad casticista se presenta contra reformista, antimoderna, y, desde luego, poco occidental, a diferencia de lo que él sostiene.

No es el PAN el que tiene un sentimiento de hispanidad. Es todo México, pues se trata de una cuestión de historia y normalmente los mexicanos aceptamos la historia como un dato ineludible y que no queremos borrar de nuestras vidas. Sabemos que hay dos raíces de México, la indígena y la española y, cualesquiera que sean los defectos o las virtudes de esas raíces, son nuestras y no admitimos su negación (Wilkie y Monzón, 1978, p. 136).

En la actualidad, el hispanismo cristiano comienza a ser desplazado por una realidad que todavía no se puede definir pero que cada vez más se configura como híbrida. La multiculturalidad, con todos sus defectos, es un fenómeno que se impone con toda la fuerza. 


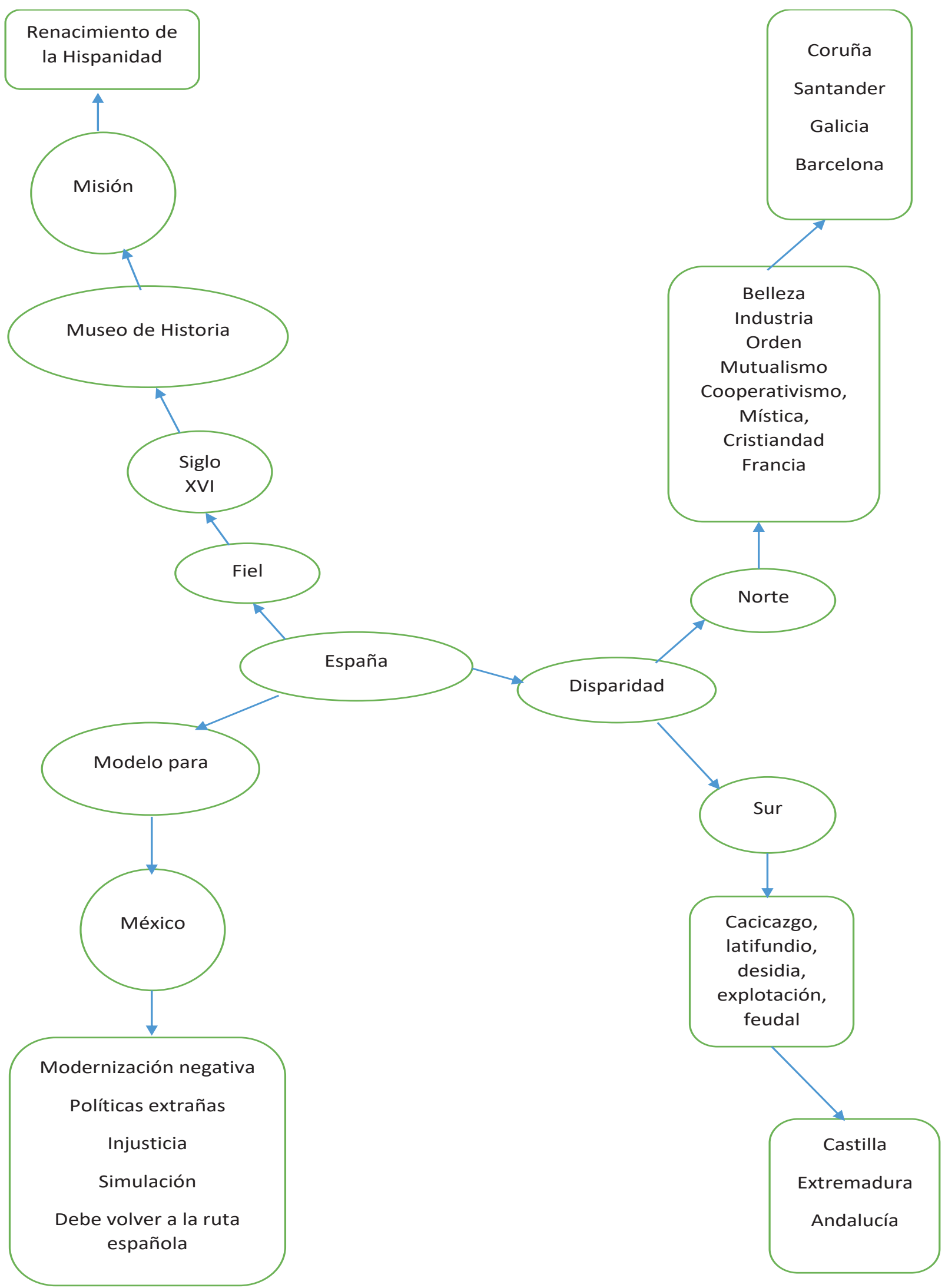

Imagen 1. Teoría Fundamentada de España Fiel 


\section{Bibliografía}

Alberro, S. (1992). Del gachupín al criollo o de cómo los españoles de México dejaron de serlo. México: Colegio de México.

Arriola, C. (2008). El miedo al gobernar. La verdadera historia del PAN. México: Océano.

Aspe, M. L. (2008). La formación social y política de los católicos mexicanos. La Acción Católica Mexicana y la Unión Nacional de Estudiantes Católicos, 1929-1958. México: Instituto Mexicano de Doctrina Social Cristiana, Universidad Iberoamericana.

Badie, B. y Hermet, G. (1993). Política comparada. México: Fondo de Cultura Económica.

Barajas R. (2014). La raíz nazi del PAN. México: El Chamuco.

Bartra, R. (2009). Gobierno, derecha moderna y democracia en México. México: Herder.

Berger, P. y Huntington, S. (comp.). (2002). Globalizaciones múltiples. La diversidad cultural en el mundo contemporáneo. Barcelona: Paidós.

Calderón, G. (2015). Manuel Gómez Morín: Entre generar y conservar. En Horizontal, revista electrónica. Recuperado en 11 de noviembre de 2016 de https://horizontal.mx/manuel-gomez-Morín-entre-generar-y-conservar/

Campbell, H. (1976). La derecha radical en México, 1929-1949. México: Secretaría de Educación Pública.

Castro, A. (1954). La realidad histórica de España. México: Porrúa.

Cosío, D. (1947). La crisis de México. México: Cuadernos Americanos.

Deras, D. (2015). En 1914, Pancho Villa expulsó a los españoles de la Laguna, Partes I, II, III, IV y V. El Siglo de Torreón. Recuperado en https://www.elsiglodetorreon.com.mx/noticia/1065400.en-1914-pancho-villaexpulso-a-los-espanoles-de-la-laguna.html

Duque, A. (1984). El suicidio de la modernidad. Barcelona: Bruguera.

Fernández de Santillán J. (2016). El PAN, entre Aristóteles y Maquiavelo. En Cansino, C. y Molina, G. (coord.). ¿Cuándo terminó de joderse México? El legado del Partido Acción Nacional (pp. 39-54). Puebla: Mariel.

Fuentes, C. (1997). El espejo enterrado. México: Fondo de Cultura Económica.

Gómez, M. (1973). España Fiel. En Gómez, M. 1915 y otros ensayos (pp. 57-77). México: JUS.

Gómez, M. T. (1996). Manuel Gómez Morín. La lucha por la libertad de cátedra. México: Universidad Nacional Autónoma de México.

González, E. (2003). Los Abascal. Conservadores a ultranza. México: Grijalbo.

González, P. (2005). El pensamiento político de la derecha española en el siglo XX. De la crisis de la Restauración al Estado de partidos (1898-2000). Madrid: Tecnos.

Huntington, S. (1996). El choque de civilizaciones. Barcelona: Paidós.

Krauze, E. (2000). Caudillos culturales en la revolución mexicana. México: Siglo XXI.

Lida, C. (2001). Presentación. El primer franquismo y sus relaciones con México. Temas y problemas. En Lida, C. (comp.). México y España en el primer franquismo, 1939-1950 (pp. 11-18). México: Colegio de México.

Loaeza, S. (1999). El Partido Acción Nacional: la larga marcha, 1939-1994. Oposición leal y partido de protesta. México: Fondo de Cultura Económica.

Loaeza, S. (2009). La hipoteca católica de Manuel Gómez Morín. Nexos, (382). Recuperado en 21 de Febrero de 2017 de: http://www.nexos.com.mx/?p=13316

Lujambio, A. (2009). Gómez Morín, el PAN y la religión católica. En Nexos, (381). Recuperado en 11 de Noviembre de 2016 de: http://www.nexos.com.mx/?p=13283

Maalouf, A. (2012). Identidades asesinas. Barcelona: Alianza editorial

Martínez, S. (1998). La patria del criollo: ensayo de interpretación de la realidad colonial guatemalteca. México: Fondo de Cultura Económica.

Mata, S. (2015). El Yunque en España. La sociedad secreta que divide a los católicos. Madrid: Amanecer. 
Mateos, A. y Sánchez, A. (2011). La crisis del antifascismo: desplome de la república española y giro del cardenismo. En Mateos, A. y Sánchez, A. (ed.). Ruptura y transición España y México, 1939 (pp. 19-32). Madrid: Eneida.

Mouffe, Ch. (2007). En torno a lo político. Buenos Aires: Fondo de Cultura Económica.

Paz, O. (2000). El laberinto de la soledad. México: Fondo de Cultura Económica.

Pérez, R. (2001). La mirada oficiosa de la hispanidad. México en los informes del Ministerio de asuntos exteriores franquista, 1940-1950. En Lida, C. (comp.). México y España en el primer franquismo, 1939-1950 (pp. 61-120). México: Colegio de México.

Pérez, T. (2005). Bestiario mexicano. El gachupín en el imaginario popular de finales del siglo XIX. En Miquel, Á., Nieto, J., Pérez, T. (comp.). Imágenes cruzadas. México y España, Siglos XIX y XX (pp. 29-52). México: Universidad Autónoma del Estado de Morelos.

Pérez, T. (2010). La difícil herencia: hispanofobia e hispanofilia en el proceso de construcción nacional mexicano. En Suárez, M. y Pérez, T. (coord.). Los caminos de la ciudadanía. México y España en perspectiva comparada (pp. 219-230). México: Siglo XXI.

Portes, E. (1964). Autobiografía de la Revolución mexicana. Un tratado de interpretación histórica. México: Instituto Mexicano de Cultura.

Recio, G. (2017). El abogado y la empresa. Una mirada al despacho de Manuel Gómez Morín, 1920-1940. México: Universidad Nacional Autónoma de México.

Rodríguez, O. (2004). Derechas y ultraderechas en el mundo. México: Siglo XXI.

Rodríguez, O. (2014). Derechas y ultraderechas en México. México: Orfila.

Ruiz de Gordejuela, J. (2012). Vasconavarros en México. España: editorial empresarial.

Sepúlveda, I. (2005). Los sueños de la madre patria: Hispanoamericanismo y nacionalismo. Madrid: Marcial Pons.

Sevilla, R. (2005). La revolución mexicana y la opinión pública española. España: Ministerio de Educación y Ciencia y Consejo Superior de Investigaciones Científicas.

Solís, Y. (2010). Un posible arquetipo de la ultraderecha en México: la "U”. En Savarino, F. y González, J. L. (coord.). México: escenario de confrontaciones (pp. 105-140). México: Escuela Nacional de Antropología e Historia, Instituto Nacional de Antropología e Historia, Consejo Nacional para la Cultura y las Artes.

Stavans, I. y Jaksic, I. (2011). ¿Qué es la hispanidad? Una conversación. Santiago de Chile: Fondo de Cultura Económica. Touraine, A. (2000). Crítica de la modernidad. México: Fondo de Cultura Económica.

Wilkie, J. y Monzón, E. (1978). Entrevistas con Manuel Gómez Morín. México: JUS.

Womack, J. (1985). Zapata y la revolución mexicana. México: Siglo XXI. 